\title{
Botanic component in training bachelors of ecology at the Siberian State University of Geosystems and Technologies (SSUGIT)
}

\author{
Tatyana Fershalova ${ }^{1 *}$, and Irina Bochkareva ${ }^{2}$ \\ ${ }^{1}$ Central Siberian Botanical Garden SB RAS, 630090 Novosibirsk, Russia \\ ${ }^{2}$ Siberian State University of Geosystems and Technologies, 630108 Novosibirsk, Russia
}

\begin{abstract}
Ecologist is among the specialties in high demand, especially under the conditions of urban environment. Plant knowledge is an essential component in preparing ecology students to academic, research and development activities. Plants knowledge gained through education is an important element for diagnostics and improvement of the ecological environment affected by various anthropogenic and natural factors. Education involves practical courses aimed at consolidation of the skills for plant identification, phyto indexing and formulation of recommendations on environmental optimization. It is shown that the application of interdisciplinary approach to the formation of universal competence through learning botany is relevant.
\end{abstract}

\section{Introduction}

Training of specialists in Ecology and Nature Management, to educate bachelors in Nature Management, includes many subjects. The students at the University start to study plants within such courses as Biology, Biogeography, Soil Science, Ecology, Landscape Science, Foundations of nature Management, Ecological Foundations of Landscape Gardening and Phytodesign.

Further on, to complete practical courses successfully, both in auditorium and under field conditions, future graduates are to apply their knowledge on plants. For example, this knowledge is necessary when learning map-based methods of environmental studies, remote and geoinformation technologies in ecology, foundations of topography, ecological monitoring, natural resources inventory, implementation of environmental laws in the region, ecological modeling, specially protected natural areas.

So, students understand that studying plants is one of the most important components of ecological research. Species composition, physiognomic appearance, structure, vital state of plants and plant communities depict all the features of habitat conditions (climate, soils, positions in the ground elevation profile), development history and links between the elements of the community, both in space and in time. The degree of ecological well-being of the environment may be assessed through the state of plants [1].

*Corresponding author: fershalova@yahoo.com 
During studying, the students gain the skill of collecting information on plants, analyzing it and predicting events that might happen due to distortions of plant communities. The most important aspect in the studies of botany in the University is the application of interdisciplinary approach. With this educational system, two directions are successfully combined: scientific (research carried out with practical objects) and technological (practical work and skill training). The gained set of knowledge is used by the students, future specialists in ecology, as a scientific basis for monitoring and practical recommendations on the improvement of urban environment.

The goal of the work was to teach students to apply their knowledge on botanical objects to monitoring, prediction of ecological situation, and development of recommendations aimed at the improvement of urban environment.

\section{Material and methods}

The methodological basis of teaching was interdisciplinary approach, which improves the quality of training the graduates of higher educational establishments [2]. The methods used in studying plants included observation, identification, classification, route and stationary survey, geobotanical description, biomorphology, phytoindication. Ecological research was carried out according to the generally accepted procedure [3]. The basis of the works aimed at the studies of plants in their natural habitat was route survey. Geobotanic descriptions were carried out according to a common procedure [4]. Plant identification was carried out with the help of literature sources and Internet resources [5-8]. Phytoindication of ecological regimes was carried out according to ecological scales proposed by H. Ellenberg [9], Y.P. Didukh [10]. The list of plants that need to be protected was compiled on the basis of the Red Book of the Novosibirsk Region [11], and the list of invasive plants - according to the Black Book of the flora of Siberia [12]. Selection of the assortment of plants that possess the properties improving the environment was carried out on the basis of materials reported by L.N. Chindyaeva et al. [13]. To provide correct identification of plants under field conditions, enormous illustrative material has been collected at the Chair of Ecology and Natural Management: herbarium in which 80 species of higher vascular plants from 33 families and 70 genera are presented. The herbarium also contains 15 moss species, 20 lichen species. Each sheet of the herbarium contains plants with a label in which the data on the geographical coordinates of sampling site and the habitat are present. Annotated list of plant objects was composed on the basis of the samples included in the herbarium: the species and named in Latin and in Russian, the features of the ecology of the species are included. There is a separate list of plant species that most frequently occur at urban areas and need protection. Along with endangered species, the students learn invasive species that bring danger to aboriginal plants. As a teaching aid, a presentation has been prepared, based on the photographs of floristic objects; the number of images is 250 [14].

Research work of the students aimed at plant studies was carried out at model sites in Novosibirsk city. The role of a reference site was played by the territory of the CSBG SB RAS, while the site with high anthropogenic load was in the Lenin District of Novosibirsk.

\section{Results}

For successful assimilation of the education plan, the work with the students is divided into three stages: preparative, field, and cameral.

The preparative part takes place in auditoriums, libraries and includes collection and treatment of literature and file materials on the territories under investigation to evaluate the state of the natural environment, and studies of the plants growing at the territory of the 
city. The skill to identify plants allows exploration of the diversity of plants under field conditions and rapid determination of plant species.

Practical training aimed at getting acquainted with the living botanical objects starts from the visit to the Botanical Garden, which is a specially protected natural territory characterized by a great variety of plant communities. Within the boundaries of the Botanical Garden, natural forest accounts for about a half of the total area, which is 850 ha. This educational ground allows observations of the features of propagation and development of 1894 taxons of algae, lichens, fungi, bryophytes and higher vascular plants [15]. In addition, there is an arboretum (dendrarium) at the territory of the Botanical Garden, where more than 500 species, hybrids and cultivars of woody plants are presented [16]. The students distinguish phytocenoses and classify the vegetation of the region under investigation. Geobotanic descriptions with the indication of ecological conditions are made in field diaries. Photographic evidence and herbarium materials are collected by the students for further studies in auditoriums and for supplementing the herbarium.

Ecological evaluation of urban territories using the plants of different taxons as indicators is carried out in the Lenin District of Novosibirsk, in the direct vicinity of the University. The objects of investigation are the plants under substantial anthropogenic load: growing along roads and streets, in the yards of residential areas. At this stage, the mutual effects of the urban environment and plants are investigated. Two directions are to be analyzed by the students. The first one involves consideration of plants as thermoregulators and phytofilters from pollutants and noise, the landscape-related, sanitary and hygienic roles of plants are evaluated, as well as their recreational and esthetic significance. This aspect of plant studies is directly related to the improvement and restoration of human habitat and to meeting the human ecological needs. The second direction relates to the studies of the effect of the factors of urban environment on the vitality of plants themselves. At this stage of education, the knowledge of phytoindication method is improved through practical skills: phytoindication, being a part of bioindication, is the applied area in ecology for the evaluation of ecological factors from the biological component of the nature. The tasks to be fulfilled by the students include: identification of plants, revelation of the species indicating the ecological settings. Students provide evaluation of the state of vegetation on the basis of the knowledge of plant morphology. Plants of different taxons are used for phytoindication-based evaluation of the environmental state: coniferous and deciduous trees, herbaceous plants.

For lichen-based indication, lichen accounting on tree bark is carried out [6]. An increase in anthropogenic load, which is enhanced in city center and near industrial enterprises, manifests itself as depletion of the species composition, a decrease in the average projective lichens coating, till their complete absence or the change of the substrate. For example, in undisturbed forests the species of such genera as Physcia, Phaeophyscia, Physconia, Caloplaca usually live on willows and poplars, but under urban conditions they frequently occur on Betula pendula. In addition, the species typical for deciduous trees - Lecania cyrtellina, Physcia dubia and Ph. Stellaris - can be frequently found on pine in many districts of the city [17]. The appearance of lichens can also be a signal of air pollution: fragmentation of soredium blastema in Physcia species, blastema tuberosity in Vulpicida, Parmelia, Hypogymnia species [18]. So, during practical training, the students are to detect lichens, analyze their appearance and the substrate on which the lichens grow. With an increase in anthropogenic load, the species diversity and abundance of lichens decrease, and dominants in lichen communities change [17]. In trees and herbaceous plants, responses to technogenic pollution include morphological, anatomical, physiological-biochemical changes. The parameters that are used most frequently and are detected visually include the structural-functional changes in leaves, a decrease in leaf size, chlorosis and necrosis, for herbaceous plants these parameters include the uniformity of 
cover, grass canopy closeness, and leaf color. Indicating plants are representatives of different botanic families: Betulaceae Gray, Malvaceae Juss., Oleaceae Hoffmanns. \& Link, Pinaceae Lindl., Rosaceae Juss., Salicaceae Mirb., Sapindaceae Juss., Ulmaceae Mirb., [19-21]. An essential component of students' work at the urban territories is revelation and determination of the plants related to endangered and invasive species.

The final stage includes structural arrangement of the collected information. Future ecologists must be able to carry out systemic ordering of the material collected during practical training. Cameral work proceeds in the auditoriums of the University. Results of field studies, namely geobotanic descriptions and the results of phytoindication, are included into the united database and analyzed. According to the results of cameral treatment, the students prepare conclusions and recommendations concerning the measures to be taken in preventing and reducing the negative action on the environment. The list of compulsory measures includes the plants from different botanic families possessing environment-improving properties. The students get acquainted with this assortment composed of more than fifty species during the field training [12].

\section{Discussion}

To train specialists capable of collecting diverse information, analyzing it and providing correct predictions of the trends, a significant botanical component is necessary in the schedules of the professional training of ecologists. Without biomorphology as a part of botany, without knowing the adaptation possibilities of plants and their responses to ecological changes of the environment, it is impossible to present professionally sound recommendations aimed at the improvement of the environment. Solutions taken by future specialists should be evaluated from the viewpoint of conservation of natural resources, ecological safety, arrangement of the environment which would be harmonic to humans. The efficiency of the formation of universal competence increases substantially due to the application of interdisciplinary approach. The consequences of solutions under the conditions of multivariance are strongly dependent on the conclusions that will be made by specialists in ecology.

The work was carried out within the framework of the State Assignment for the Central Siberian Botanical Garden SB RAS. When preparing the publication, the materials of bioresource scientific collection of CSBG SB RAS «Collections of living plants indoors and outdoors», USU 440534 were used.

\section{References}

1. Yu. A. Mandra, A. N. Esaulko, P. V. Klyushin, E. E. Stepanenko, T. G. Zelenskaya, South of Russia: ecology, development, 14 (4) (2019)

2. I. V. Lysak, Modern problems of science and education, 5 (2016)

3. O. V. Bayanova, S. L. Maksimova, Methods of research activities in ecology (Tyumen, 2013)

4. AField Geobotany, Vol. 4 (Nauka, Leningrad, 1972)

5. I. M. Krasnoborov, M. N. Lomonosov, D.N. Shaulo, E.I. Vibe, O.S. Zhirova, E.A. Korolyuk, A.A. Krasnikov, O. N. Snytko, N.N. Tupitsyna, Keys to Plants of the Novosibirsk Region. (Novosibirsk, Nauka, 2000)

6. T. N. Vstovskaya, I. Yu. Koropachinsky, Keys to local and exotic woody plants of Siberia (Nauka, Novosibirsk, 2000) 
7. E. V. Romanova, N. V. Sedelnikova, Lichens-bioindicators of atmospheric pollution of the Novosibirsk urban agglomeration (Geo, Novosibirsk, 2010)

8. Plantarium: Plants and lichens of Russia and neighboring countries: an open online atlas and key to plants. https://www.plantarium.ru/

9. H. Ellenberg, Vegetation ecology of Central Europe (University Press, Cambridge, 1988)

10. Ya. P. Didukh, The ecological scales for the species of Ukrainian flora and their use in synphytoindication (Phytosociocentre, Kyiv, 2011)

11. Red Data Book of the Novosibirsk Region: Animals, Plants and Fungi (Printing House of Andrey Khristolyubov, Novosibirsk, 2018)

12. Black Book of Siberian flora (Geo, Novosibirsk, 2016)

13. L. N. Chindyaeva, N. V. Tsybulya, T. I. Kiseleva, Problems of balneology, physiotherapy, and exercise therapy, 97, 4 (2020)

14. T. D. Fershalova, T. S. Chernikova, Y. S. Otmakhov., I. I. Bochkareva, Modern problems of science and education 2 (2019)

15. Plant diversity of the Central Siberian Botanical Garden SB RAS (Geo, Novosibirsk, 2016)

16. L. N. Chindyaeva, A. A. Gonchar, Landscape art of Siberia: landscapes and landscape compositions of the Novosibirsk Academgorodok (Arta, Novosibirsk, 2008)

17. E. V. Svirko, Siberian Botanical Bulletin, 1 (2006)

18. O. A. Neverova, Biosphere, 1, 1 (2009)

19. M. K. Kazimagomedov, South of Russia: ecology, development, 8, 4 (2013)

20. L. K Trubina, E. P Khramova, A. Yu. Lugovskaya, Vestnik SGUGiT 4, 36 (2016)

21. V. S. Alekhina, E. V. Mironenko, Bulletin of the Buryat State Agricultural Academy named after V.R. Fillipova, 1, 50 (2018) 